Eos, Vol. 77, No. 18, April 30, 1996

E O S, TRA N A C T I O S, A M E R I A N G E O P H Y I C A L U N I O N

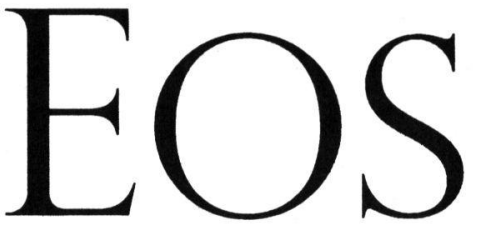

VOLUME 77 NUMBER 18

APRIL 30, 1996

PAGES 173-180

\title{
Images of Crust Beneath Southern California Will Aid Study of Earthquakes and Their Effects
}

PAGES 173,176

Gary S. Fuis, David A. Okaya, Robert W. Clayton, William J. Lutter, Trond Ryberg, Thomas M. Brocher, Thomas M. Henyey, Mark L. Benthien, Paul M. Davis, James Mori, Rufus D. Catchings, Uri S. ten Brink, Monica D. Kohler, Kim D. Klitgord, and Robert G. Bohannon

The Whittier Narrows earthquake of 1987 and the Northridge earthquake of 1991 highlighted the earthquake hazards associated with buried faults in the Los Angeles region. A more thorough knowledge of the subsurface structure of southern California is needed to reveal these and other buried faults and to aid us in understanding how the earthquake-producing machinery works in this region.

Crustal structure models based on earthquake tomography [e.g., Hearn and Clayton, 1987] are too general to reveal buried faults and other important details, given the wide spacing of permanent seismographic stations and the imprecise locations of earthquakes. Structure models based on drill holes and structural geology [e.g., Davis and Namson, 1989; Wright, 1991] are limited in depth resolution. We need to understand the subdivision of the crust into blocks, the properties of the blocks, how they are coupled, and how stress is being applied. Such knowledge needs to extend well below seismogenic depths (10-20 km) to include all contributing structures. We also need to understand where earthquake shaking is likely to be amplified at the surface, and this requires knowledge especially of sedimentary basins in the upper part of the crust [e.g., Olsen et al., 1995].

To study the crustal structure of Southern California, the U.S. Geological Survey and the Southern California Earthquake Center initiated a seismic imaging program known as the Los Angeles Region Seismic Experiment

For more information, contact Gary S. Fuis, U.S. Geological Survey, 345 Middlefield Rd., Menlo Park, CA 94025.
(LARSE). Preliminary crustal images from LARSE, including a cross section northeastward across the Los Angeles basin, San Gabriel Mountains, and southern Mojave Desert ("Line 1") reveal the depth and configuration of sedimentary basins and seismic-velocity structure within basement

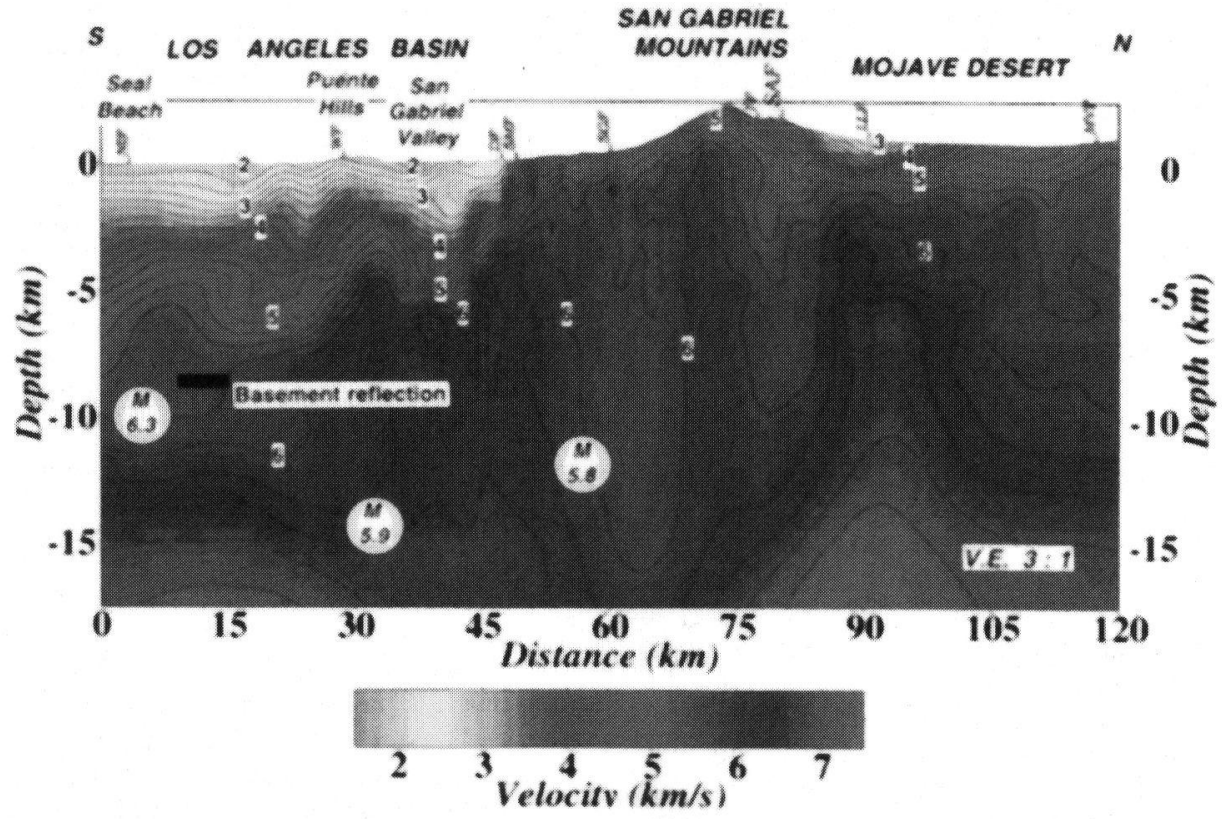

Fig. 1. Preliminary seismic-velocity model along part of line 1 (see Figure 2) obtained from inverting first-arrival travel times from explosions. Seismic-velocity contour interval, $0.25 \mathrm{~km} / \mathrm{s}$; integer velocities are labeled. Hypocenters for three moderate earthquakes have been projected onto the model (see Figure 2). Black bar indicates depth of sediment-basement interface modeled from a wide-angle reflection in this region. NIF, Newport-Inglewood fault; WF, Whittier fault; DF, Duarte fault; SMF, Sierra Madre fault; SGF, San Gabriel fault; PF, Punchbowl fault; SAF, San Andreas fault; LLF, Llano fault; and MVF, Mirage Valley fault. Vertical exaggeration 3:1. Original color image appears at the back of this volume. 
Fig. 2. Fault map of Los Angeles region [Jennings, 1975] showing locations of sources and receivers for October 1994 LARSE air gun and explosion surveys. $C B F$, Catalina basin fault; $S P B F$, San Pedro basin fault; PVHF, Palos Verde Hills fault; other abbreviations are defined in the caption below Figure 1. Through the northern Los Angeles basin and San Gabriel Mountains, $m$ apart and the seismographs $100 \mathrm{~m}$ apart to produce both a reflection and refraction image of the crust. Original color image appears at the back of this volume. shots were spaced 1000

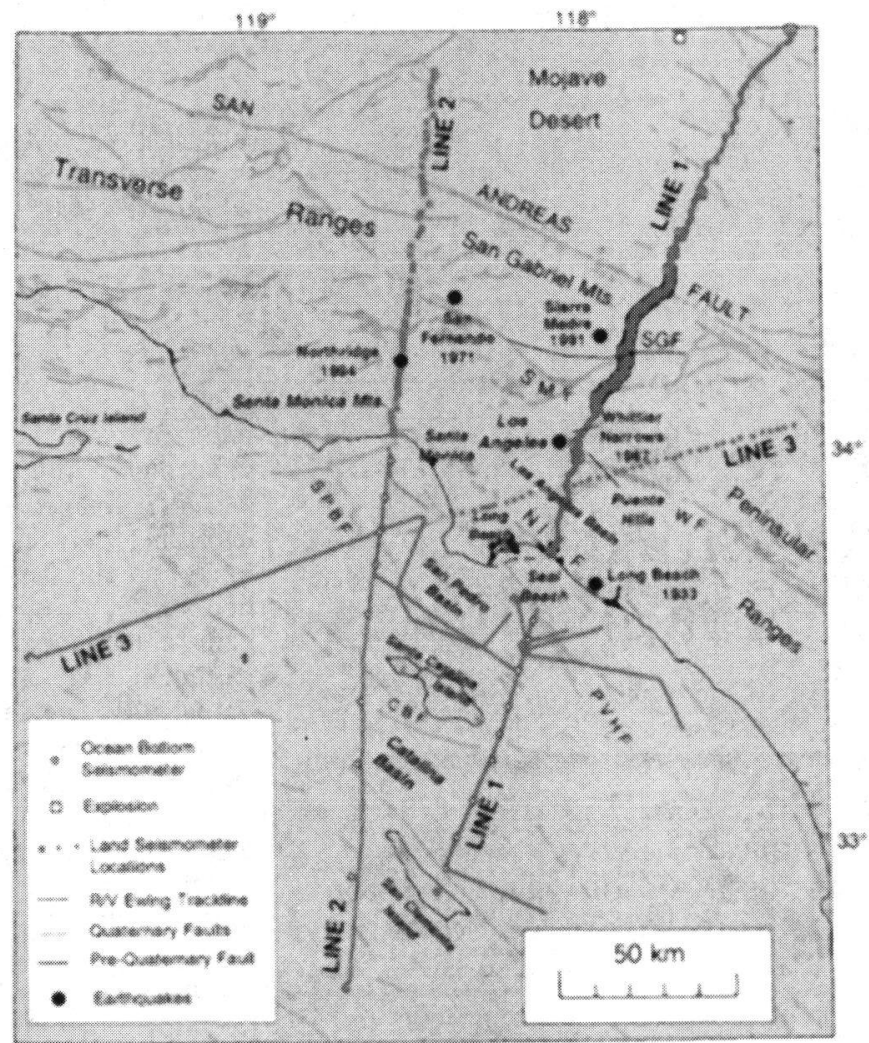

fault zone or some combination of erosion and tilting along the mountain front to prevent the hanging wall of the fault from becoming superposed on the sediments. The San Andreas fault and a former branch, the San Gabriel fault (SAF and SGF, respectively, Figure 1), are imaged as approximately vertical low-velocity-zones penetrating as deeply as $10 \mathrm{~km}$. Further refinement of this image may reveal what happens at the intersection of these two faults with the north-dipping Sierra Madre fault (not yet clear in this image), allowing us to see how the blocks fit together beneath the San Gabriel Mountains.

\section{Experiment Design and Data Acquisition}

LARSE began in 1993 (LARSE93) with a passive experiment along line 1 (Figure 2). The objective of this experiment was to collect seismic waveform data from local and teleseismic earthquakes to refine three-dimensional images of the lower crust and upper mantle in Southern California, especially in the San Gabriel Mountains and across the San Andreas fault.

In October 1994, we conducted air-gun and explosion surveys along three lines, including line 1, which crossed the Los Angeles region and the offshore Continental Borderland (LARSE94; Figure 2). The $R / V$ Ewing, of Lamont-Doherty Earth Observatory, towed an air gun array along multiple passes of the offshore extensions of lines 1-3. The air guns were recorded by a 4 -km-long streamer, 10 ocean-bottom seismographs, and 170 onshore seismographs. This survey was followed by over 60 explosions (5-3000 kg) along the onshore part of line 1 that were recorded by a stationary linear array of 640 seismographs. The explosion survey was designed as a combined reflection and refraction experiment to complement the air gun survey. Existing seismic-reflection and well-log data from the oil industry will be used to determine the structure of the upper parts of sedimentary basins along all three lines.

LARSE94 required unusual emphasis on several aspects of seismic data acquisition in the urban environment. The permitting process, which took 2 years, required not only an environmental assessment but addresses to city councils and other governmental bodies, extensive radio, television, and newspaper interviews, and correspondence with many individuals and private groups. The public reception of this high-profile experiment was generally positive, owing in large part to the recent Northridge earthquake and other earthquakes in the Los Angeles region.

However, security for the seismographs required, in many cases, complete burial of the recorder and batteries. Noise suppression required up to 6 passes along the offshore segments of the three lines with the air-gun sources with a plan to stack the data. It also required an extensive pre-experiment noise survey, avoidance of freeways, and detonation of explosions between the hours of 1:30 and 4:30 a.m. Care had to be taken to avoid damage-perceived and real-from the explosions.

The chief targets along offshore line 1 were the Catalina, San Pedro basin, and Palos Verde Hills faults (Figure 2). The chief targets along onshore line 1 were the top of basement beneath the Los Angeles basin, which had never before been imaged [Wright, 1991], the Elysian Park blind thrust fault system, believed to be the causative structure for the M 5.9 Whittier Narrows earthquake of 1987 [Hauksson et al., 1988], the Sierra Madre fault system, believed to be the causative structure for the M 5.8 Sierra Madre earthquake of 1991 [Hauksson, 1994], and the San Andreas fault.

LARSE94 was designed to image these features using vertical-incidence and wideangle reflections and also detailed seismic-velocity models, in which the faults might appear as discontinuities or as tabular low-velocity zones. Data obtained during the experiment was generally of good quality. Air gun signals recorded by the streamer produced crisp images of offshore sedimentary basins and faults [Brocher et al., 1995]. Air gun signals recorded at ocean-bottom seismographs were commonly visible to $70-\mathrm{km}$ range, and some to as much as 140-km range. Air gun signals recorded at onshore seismographs were visible at many sites in the Los Angeles basin during nighttime passes and carried over $200 \mathrm{~km}$ to sites in the Mojave Desert. Land-explosion signals were generally clearly visible throughout the San Gabriel Mountains and the Mojave Desert. At seismograph sites in the Los Angeles basin, however, only explosions within the basin produced clear signals.

\section{LARSE Results}

Teleseismic $P$ wave residuals from events recorded during LARSE93 increase on average by $0.7 \mathrm{~s}$ from the San Gabriel Valley to the northern San Gabriel Mountains. The residuals show little dependence on back azimuth or incidence angle, indicating a shallow origin, such as northward crustal thickening or northward seismic-velocity decrease in the middle or lower crust [Kohler et al., 1995]. Velocity variation in the upper crust (see Figure 1) is insufficient to explain the residual pattern.

Two preliminary crustal images from the land explosions in LARSE94 are shown (Figures 1 and 3 ). The upper crustal seismic-velocity structure along line 1 (Figure 1) was obtained from inversion of first-arrival travel times from the explosions. An image of reflections (second arrivals) beneath the San Gabriel Mountains was obtained from a "brute" stack of the explosion seismograms (Figure 3).

The inversion technique used to produce Figure 1 is that of Lutter et al. [1990]. This inversion is preliminary, and important details will change in future analysis; however, several major features are suggested that most likely will endure, including some features we targeted for imaging (see above).

Seismic velocities less than $5.5 \mathrm{~km} / \mathrm{s}$ extending more than $7 \mathrm{~km}$ beneath the southern part of the Los Angeles basin suggest the presence of sedimentary and volcanic rocks. 


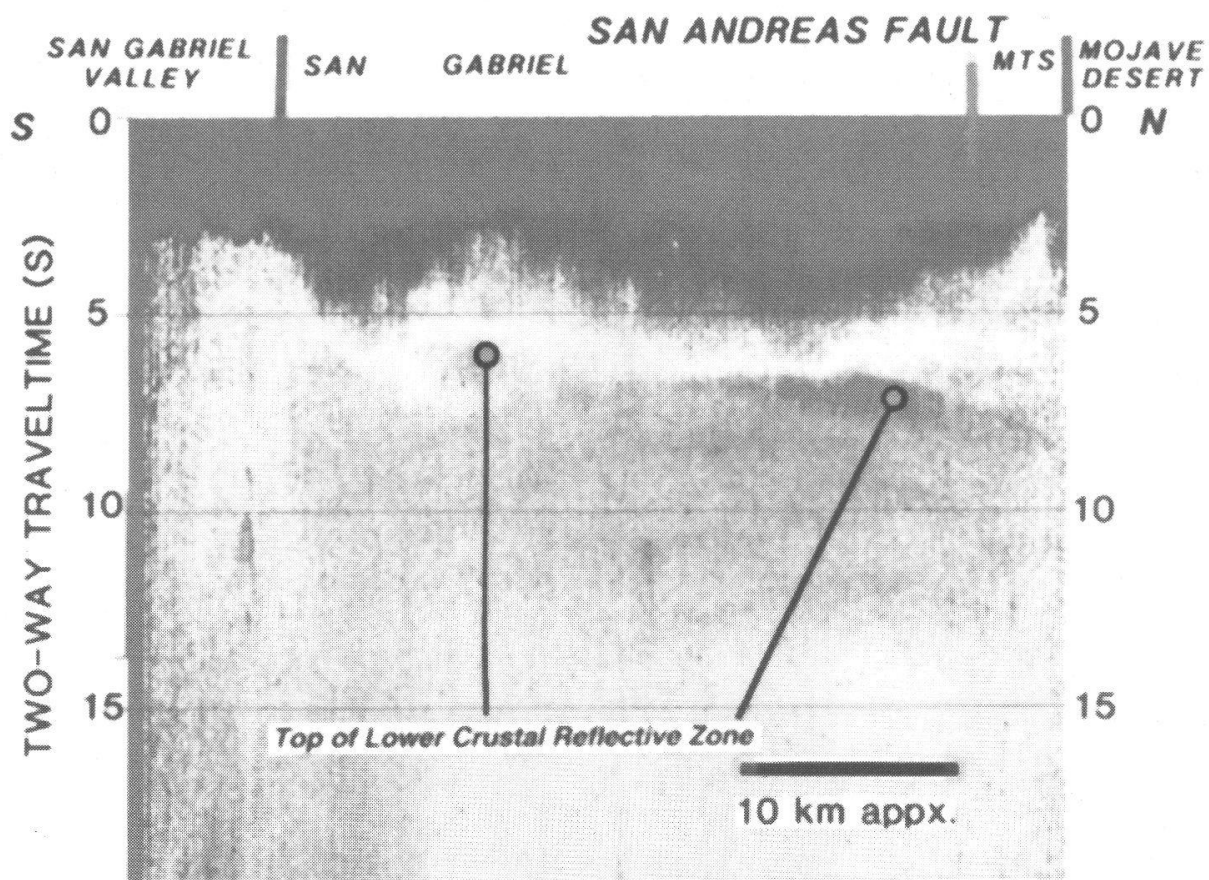

Fig. 3. "Brute" stack of explosion seismograms. Faint reflections (or echos) from deep rock interfaces have been enhanced in this image by adding together (or "stacking ") seismograms that have the same midpoints. Midpoints are locations on the Earth's surface vertically above the subsurface bounce (or echo) points for energy traveling between different explosions and recorders. As many as 40 seismograms are stacked at each midpoint (each grainy line) in the central part of this image. This image is color coded: red (and dark blue within the red) indicates highly reflective area 5, whereas blue and green indicate areas with low reflectivity. Note that the part of the crust shown in Figure 1 lies almost entirely above the highly reflective zones shown here, whose top is at approximately 16-to 19-km depth (5.5 to $6.5 \mathrm{~s}$; see text). Original color image appears at the back of this volume.

Independent modeling of a strong wide-angle reflection in this region indicates a sediment-basement interface at about $8.5-\mathrm{km}$ depth (black bar, Figure 1). This reflection provides the first clear image of the bottom of the Los Angeles basin [cf., Wright, 1991].

A south verging velocity "high" defined by upbowed velocity contours that are asymmetric toward the south is visible beneath the Puente Hills. This feature agrees with the cross sections of Davis and Namson [1989] and Wright [1991], which show one or more basement blocks thrust southward over sedimentary rocks of the Los Angeles basin. The 1987 Whittier Narrows M 5.9 earthquake, which occurred $6 \mathrm{~km}$ northwest of line 1 [Hauksson et al., 1988] (Figures 1 and 2), is believed to have occurred on a blind thrust fault into which these faults merge at depth.

A 5-km maximum depth to basement, exceeding previous estimates [cf. Wright, 1991], was observed in the northern part of the Los Angeles basin, or San Gabriel Valley. The basement rises abruptly from $5-\mathrm{km}$ depth to the surface within less than 10-km distance on the north side of the San Gabriel Valley. This geometry shows that no significant volume of low-velocity sedimentary rocks is carried beneath the San Gabriel Mountains along the north dipping Sierra Madre fault.
Nearly vertical low-velocity zones are centered on the San Gabriel and San Andreas faults. Both low-velocity zones approach 10 $\mathrm{km}$ in width, penetrate to as much as $10-\mathrm{km}$ depth, and represent velocity reductions of as much as $0.5 \mathrm{~km} / \mathrm{s}$.

It is interesting that low-velocity zones, presumably originating from cracks and/or alteration, persist in about equal strength and definition along both faults, even though the San Gabriel fault (an older strand of the San Andreas fault) is inactive in the vicinity of line 1 [Jennings, 1975]. Future refinement of this tomographic image may reveal that parts of both low-velocity zones are associated with adjacent faults.

Prominent reflections are observed beneath most of the San Gabriel Mountains beginning at 5.5 to $6.5 \mathrm{~s}$ two-way travel time (Figure 3). These reflections form arched zones that are more or less concentric and persist to 12- or 13-s travel time. The shallowest reflectiive zone, in the southern part of the range, begins at about $16-\mathrm{km}$ depth. The strongest reflective zone, in the northern part of the range, begins at about 19-km depth, and appears to extend across the deep vertical projection of the San Andreas fault; however, this apparent relationship will change somewhat when the data are migrated.
In any case, the top of these reflective zones represents a "block" boundary, or change in rock properties, in the crustal framework of southern California. The top may be a fault contact (decollement) or an igneous contact, and it may be young or old.

These preliminary images from LARSE indicate that we succeeded in imaging many of our targets. These and other images gathered during LARSE will be brought into better focus with additional analysis and will lead us a bit farther toward our goals of outlining the geometry and structural relationships of major crustal blocks in the Los Angeles region and in outlining the configuration of sedimentary basins.

\section{Acknowledgments}

The National Earthquake Hazards Reduction Program and the National Science Foundation funded this experiment. We thank David Hill, Thomas Holzer, and Walter Mooney for reviews of early versions of this paper.

\section{References}

Brocher, T. M., R. W. Clayton, K. D. Klitgord, R. G. Bohannon, R. Sliter, J. K.McRaney, J.V. Gardner, and J. B.Keene, Multichannel seismic-reflection profiling on the R/V Maurice Ewing during the Los Angeles Region Seismic Experiment (LARSE), California, U.S. Geol. Surv. Open File Rep. 95-228, 70 p., 3 pl., 1995.

Davis, T. L., and J. Namson, A cross section of the Los Angeles area: Seismically active fold and thrust belt, the 1987 Whittier Narrows earthquake, and earthquake hazard, J. Geophys. Res., 94, 9644, 1989. Hauksson, E., The 1991 Sierra Madre earthquake sequence in Southern California: seismological and tectonic analysis, Bull. Seismol. Soc. Am., 84, 1058, 1994.

Hauksson, E., et al., The 1987 Whittier Narrows earthquake in the Los Angeles metropolitan area, California, Science, 239, 1409, 1988.

Hearn, T. M., and R. W. Clayton, Lateral velocity variations in southern California: 1 Results for the upper crust from Pg-waves, Bull. Seismol. Soc. Am., 76, 495, 1986. Jennings, C. W., compiler, Fault Map of California, California Geologic Data Map No. 1, California Division of Mines and Geology, Sacramento, scale 1:750,000, 1975.

Kohler, M. D., P. M. Davis, M. Benthien, H. Liu, S. Gao, and G. Pei, Structural features under southern California from teleseisms recorded during the Los Angeles Region Seismic Experiment passive phase (abstract), Eos, Trans. AGU, 76, 349, 1995. Lutter, W. J., R. L. Nowack, and L. W. Braile, Seismic imaging of upper crustal structure using travel times from the PASSCAL Ouachita experiment, J. Geophys. Res., 95, 4621, 1990.

Olsen, K. B., R. Archuleta, and J. R. Matarese, Three-dimensional simulation of a magnitude 7.75 earthquake on the San Andreas fault, Science, 270, 1628, 1995.

Wright, T. L., Structural Geology and Tectonic Evolution of the Los Angeles Basin, California, in Active Margin Basins, edited by K. T. Biddle, American Association of Petroleum Geologists Memoir 52, pp. 35134, 1991. 


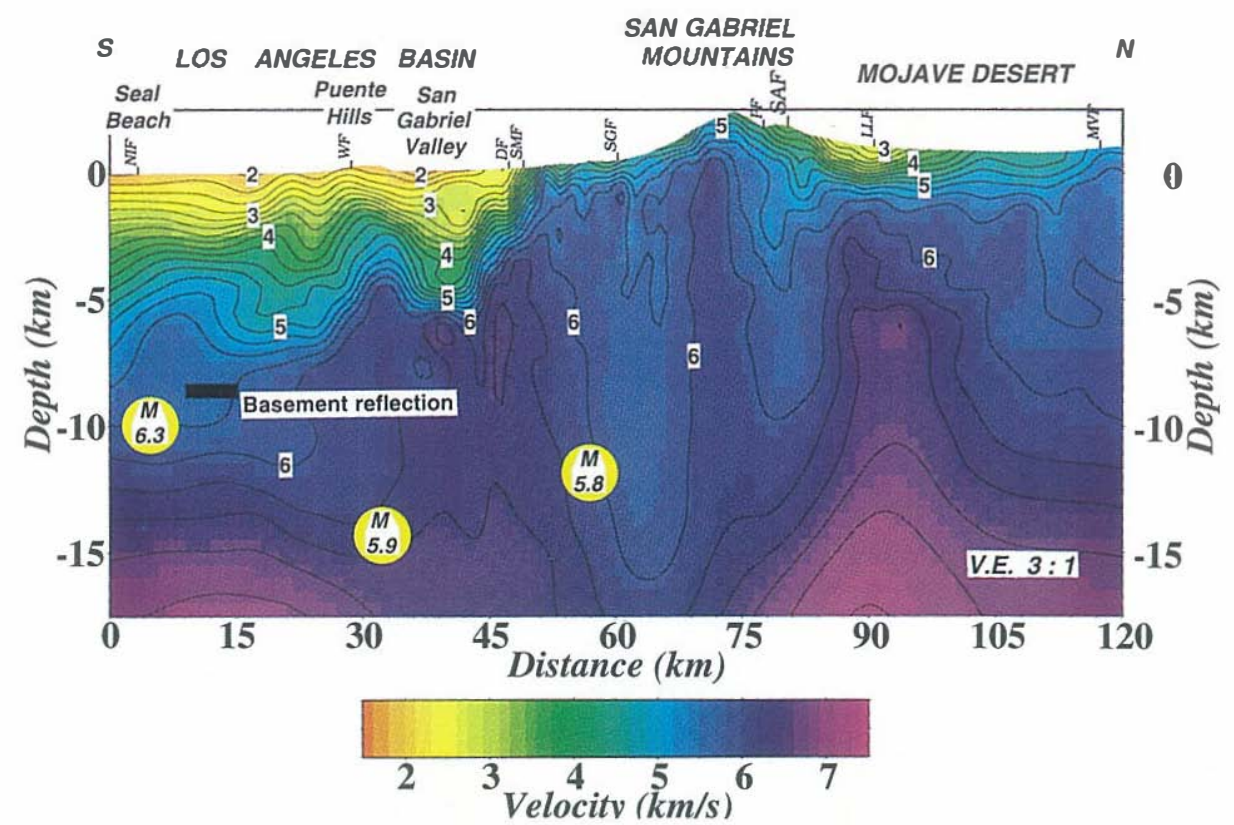

Fig. 1. Preliminary seismic-velocity model along part of line I (see Figure 2) obtained from inverting first arrival travel times from explosions. Seismic-velocity contour interval, $0.25 \mathrm{~km} / \mathrm{s}$; integer velocities are labeled. Hypocenters for three moderate earthquakes have been projected onto the model (see Figure 2). Black bar indicates depth of sediment-basement interface modeled from a wide-angle reflection in this region. NIF; Newport-Inglewood fault; WF; Whittier fault; DF, Duarte fault; SMF; Sierra Madre fault; SGF; San Gabriel fault; PF; Punchbowl fault; SAF, San Andreas fault; LLF; Llano fault; and MVF, Mirage Valley fault. Vertical exaggeration 3:].

Fig. 2. Fault map of Los Angeles region [ $\mathrm{Jen}-$ nings, 1975] showing locations of sources and receivers for October 1994 LARSE air gun and explosion surveys. CBF; Catalina basin fault; SPBF, San Pedro basin fault; PVHF; Palos Verde Hills fault; other abbreviations are defined in the caption below Figure 1. Through the northern Los Angeles basin and San Gabriel Mountains, shots were spaced 1000 $m$ apart and the seismographs 100 m apart to produce both a reflection and refraction image of the crust.

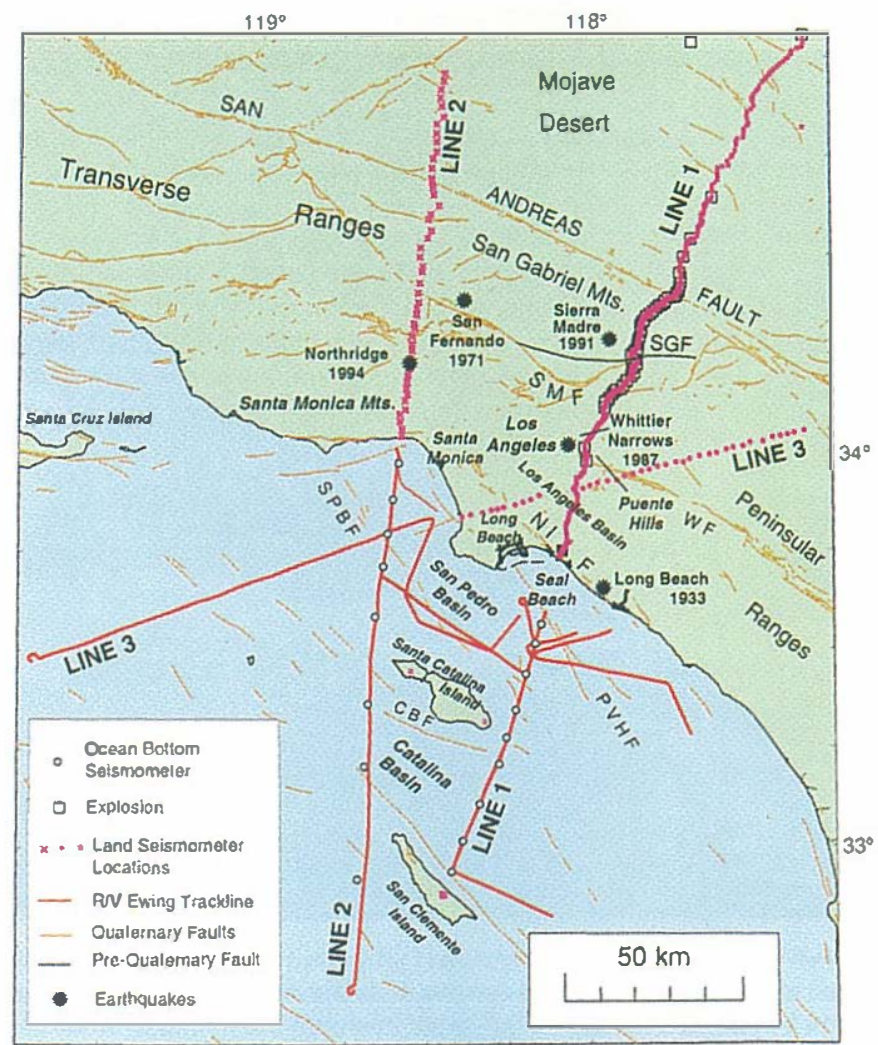




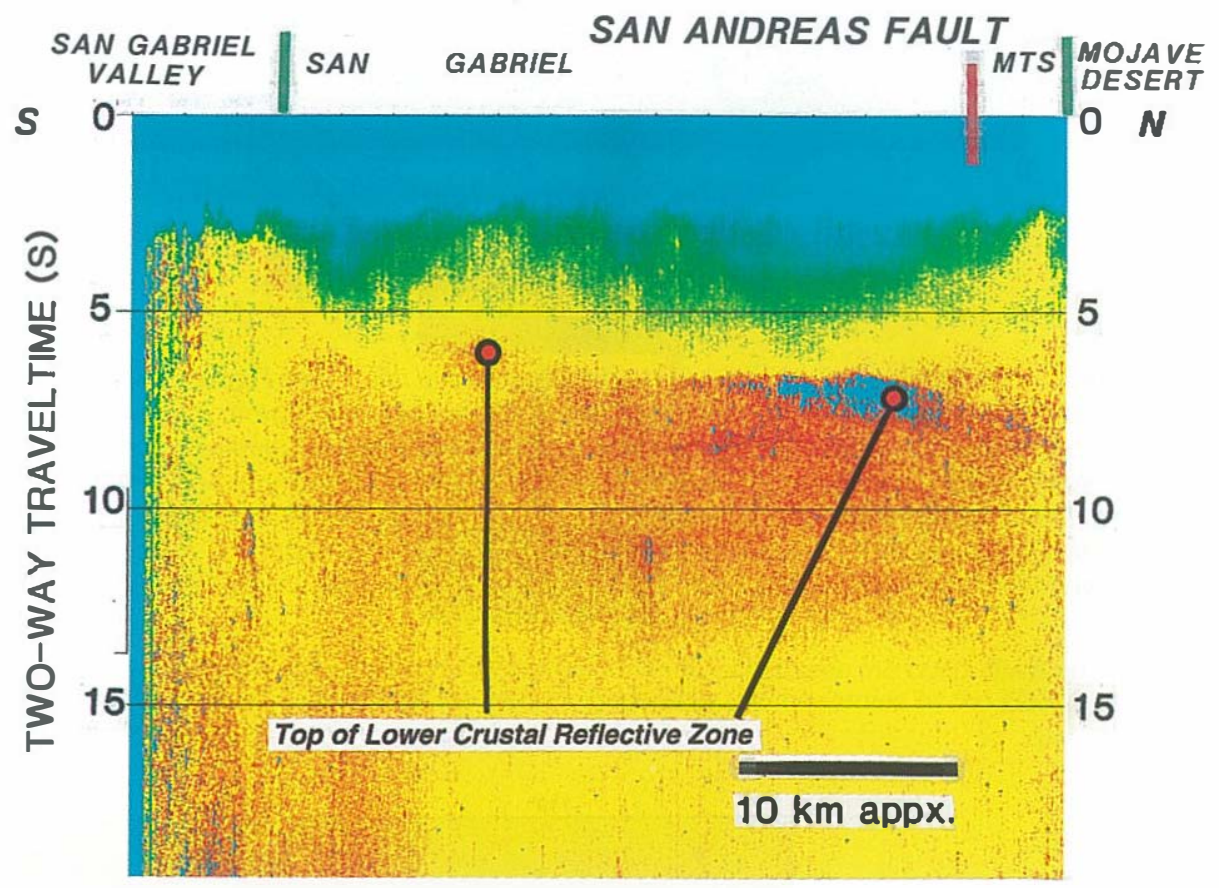

Fig. 3. "Brute" stack of explosion seismograms. Faint reflections (or echos) from deep rock interfaces have been enhanced in this image by adding together (or "stacking") seismograms that have the same midpoints. Midpoints are locations on the Earth's surface vertically above the subsurface bounce (or echo) points for energy traveling between different explosions and recorders. As many as 40 seismograms are stacked at each midpoint (each grainy line) in the central part of this image. This image is color coded: red (and dark blue within the red) indicates highly reflective area 5, whereas blue and green indicate areas with low reflectivity. Note that the part of the crust shown in Figure 1 lies almost entirely above the highly reflective zones shown here, whose top is at approximately 16-10 19-km depth (5.510 6.5 s; see text). 